\title{
Looking for the Outcomes We Love in All the Wrong Places: The Questionable Value of Biomarkers and Investments in Chronic Care Disease Management Interventions
}

\author{
Frederic R. Curtiss, PhD, RPh, CEBS, and Kathleen A. Fairman, MA
}

A ccording to Roman mythology, a handsome but vain young man, Narcissus, became thirsty while hunting in the woods. Kneeling down upon the banks of a stream, he became fascinated by his own reflection. Refusing to drink the water lest he damage the lovely image in the stream, and not realizing that he was in fact staring only at a reflection of himself, he eventually died of thirst. The tragic error of Narcissus was looking in the wrong place to meet his needs. ${ }^{1}$

Events of the past 2 years have, in sometimes disconcerting ways, demonstrated that "evidence-based" medicine has been looking in the wrong places to meet many of the most important needs of the patients it serves. The results of 4 recent large clinical trials have highlighted the limitations of conventional wisdom regarding the value of key biomarkers in predicting clinical end points, and preliminary evaluation of the Medicare Health Support (MHS) demonstration project, a randomized trial of disease management interventions that had been touted by proponents as a way to "prove that disease management can be cost-effective at a national level with a Medicare population,"2 instead produced the disappointing finding in June 2007 that the fees paid to participating vendors had "far [exceeded] savings produced."3 In 2008, the Centers for Medicare \& Medicaid Services (CMS) announced that it would terminate the MHS demonstration for failure to meet the statutory requirements necessary for its continuation, most prominently, programmatic cost savings. ${ }^{4}$ Conventional wisdom was also challenged recently when 2 Milliman Research Reports showed that (a) medical care cost increases for Medicare beneficiaries with chronic disease have been lower than the cost increases for beneficiaries without chronic disease, and (b) spending on wellness programs and chronic care management is unlikely to generate a favorable return on investment. These developments and the facts in evidence shake the foundation of many managed care interventions.

Fitch et al. in a Milliman research report informed us that the cost increases for the nonchronic Medicare fee-for-service (FFS) population have been higher over the 4-year period ended in 2006 than the cost increases for 5 chronic conditions: coronary artery disease (CAD, including angina), diabetes, chronic obstructive pulmonary disease (COPD), congestive heart failure (CHF), and asthma. ${ }^{5}$ The annual per-member cost increase for Medicare FFS beneficiaries without these 5 chronic conditions was $6.2 \%$ in $2003,9.0 \%$ in $2004,6.4 \%$ in 2005 , and $7.5 \%$ in 2007 , larger than the average annual cost increases for each of the
4 years for all chronic conditions except 3 years for asthma and 1 year for CHF (Table).

TABLE Annual PMPM Increases in Medicare Expenditures by Chronic Condition

\begin{tabular}{l|c|c|c|c}
\hline & $\mathbf{2 0 0 2 / 2 0 0 3}$ & $\mathbf{2 0 0 3 / 2 0 0 4}$ & $\mathbf{2 0 0 4 / 2 0 0 5}$ & $\mathbf{2 0 0 5 / 2 0 0 6}$ \\
\hline CAD & $4.2 \%$ & $6.0 \%$ & $5.3 \%$ & $1.5 \%$ \\
\hline Diabetes & $4.0 \%$ & $5.9 \%$ & $4.9 \%$ & $1.8 \%$ \\
\hline COPD & $4.7 \%$ & $7.2 \%$ & $6.0 \%$ & $3.2 \%$ \\
\hline CHF & $4.8 \%$ & $7.8 \%$ & $7.9 \%$ & $5.5 \%$ \\
\hline Asthma & $7.8 \%$ & $9.1 \%$ & $8.4 \%$ & $3.2 \%$ \\
\hline Chronic overall & $4.2 \%$ & $6.2 \%$ & $5.2 \%$ & $2.6 \%$ \\
\hline Nonchronic & $6.2 \%$ & $9.0 \%$ & $6.4 \%$ & $7.5 \%$ \\
\hline
\end{tabular}

$C A D=$ coronary artery disease (includes angina); $C H F=$ congestive heart failure; $C O P D=$ chronic obstructive pulmonary disease; $P M P M=$ per member per month.

However, annual cost increases do not tell the entire story. Medicare beneficiaries with chronic diseases had about 4 times higher per member per month (PMPM) costs compared with nonchronic disease beneficiaries over the 4-year period ended in 2006. Medicare FFS beneficiaries with chronic diseases in 2006 had average PMPM costs of $\$ 1,473$ versus $\$ 410$ for beneficiaries without chronic diseases. This imbalance in average cost per beneficiary means that while chronic disease beneficiaries accounted for $33.7 \%$ of the entire Medicare population in 2006, they accounted for $64.6 \%$ of total Medicare allowed spending. Still, the sustained rate of increase for the beneficiaries without chronic disease is not an expected finding.

\section{What to Expect from Wellness and Disease Management Programs}

In 2003, Sandra Foote, then Director of the Health Insurance Reform Project at George Washington University, advocated rigorous tests of the effectiveness of population-based disease management programs in improving care for chronic diseases within Medicare. ${ }^{6}$ Foote's argument that disease management pilot projects "could act as a catalyst for improving the health of chronically ill beneficiaries" was based on the common-sense idea that disease management programs might "help beneficiaries and providers increase their adherence to evidence-based guidelines." 
Bolstered by testimony of then-Director of CMS, Daniel Crippen, that $88 \%$ of Medicare spending was attributable to enrollees with 3 or more chronic conditions, ${ }^{7}$ Foote's argument was viewed by observers as "convincing" and consistent with available evidence at the time. ${ }^{8}$ Yet, much to their credit, both Foote and Crippen pointed out in 2003 that the evidence in favor of disease management's effectiveness was derived largely from methodologically weak, nonrandomized studies whose results were vulnerable to the effects of selection bias (e.g., more motivated or healthier individuals attracted to participation in a disease management program) and regression to the mean, the phenomenon by which higher-cost patients tend to incur lower costs over time without any intervention.

The sharp contrast between the early high hopes for disease management's potential to improve quality and reduce costs and the lackluster MHS results provides a case study in what happens when the pace of an innovation's development, based on a combination of weak research evidence and overreliance on intermediate measures of care rather than on end point outcomes, outstrips the availability of solid research to guide an evidencebased approach. The MHS dénouement was not entirely unexpected by those familiar with the limitations and findings of the disease management research literature. In a textbook example of regression to the mean, Rubin et al.'s 1998 study of a comprehensive diabetes care management program claimed gross savings of $\$ 50$ per diabetic patient per month and a $21 \%$ reduction in hospital bed days, based solely on a comparison of pre-intervention with post-intervention outcomes and an assumption that costs for diabetic patients would have increased at the same rate as costs for nondiabetic patients were it not for the disease management program. ${ }^{9}$ In 1999, Domurat compared screening rates (e.g., hemoglobin Alc, urinary protein, serum lipids) and hospital utilization measures for enrollees in a diabetes care program that served the highest-severity (top 30\%) diabetic patients versus lower-severity patients (the remaining 70\%). Biomarker screening rates were higher for the higher-severity (care management) group than the lower-severity (usual care) group (e.g., rates of Alc testing of $84 \%$ for care management vs. $51 \%$ for usual care, $P<0.001$; rates of serum lipid testing of $75 \%$ for care management vs. $49 \%$ for usual care, $P<0.001$ ), and inpatient utilization for the care management group decreased from baseline in 1995 (mean [SD] days 1.28 [5.93]) to 1997 (0.63 [2.24]). Although Domurat's findings were likely attributable to regression to the mean and selection bias (i.e., testing rates would typically be higher for higher-severity than lower-severity patients), he concluded that the program "appears to reduce the number of hospitalizations and improve screening rates ..."10

Disease management programs have achieved modest successes in trials with control groups. For example, Warsi et al.'s 2004 meta-analytic review and methodological critique of the literature on self-management education programs found "small to moderate" effects on intermediate end points, including biomarkers Alc and systolic blood pressure, for patients with diabetes and hypertension. ${ }^{11}$

Studies of patients with very high-severity conditions have also produced some success in modifying end point outcomes. ${ }^{12,13}$ For example, Rich et al. studied the use of nurse-directed multidisciplinary intervention, including education of patient and family, social service involvement, medication and "intensive" follow-up, in hospitalized patients aged 70 years or older and at high risk for readmission for CHF. Rates of readmission for CHF were 56.2\% lower in the treatment group than in the control group (16.9\% vs. $38.6 \%$, respectively, $P<0.04$ ). Improvements in quality-of-life measures and a reduction of $\$ 153$ per patient per month were noted as well. However, reports of successful interventions based on studies with strong designs have tended to be the exception rather than the rule, ${ }^{14,15}$ and Warsi et al. observed that even among studies with control groups, methods used in assessing disease management programs varied widely and were generally "suboptimal." 11

As with so many health care innovations that seem to make sense to everyone at the time they are developed, the weakness in the research evidence supporting disease management did not hamper its enthusiastic adoption; the disease management industry's annual revenues increased from $\$ 85$ million to more than $\$ 600$ million between 1997 and 2002. ${ }^{6}$ How the disease management industry will respond to the MHS setback is unclear. The MHS findings suggest that effective targeting of future disease management programs to beneficiaries most likely to benefit from them will continue to be challenging. Medicare beneficiaries in the MHS were randomized to equivalent intervention and control groups, but among those assigned to the intervention arm, those who actually agreed to participate in the program represented "a healthier subset of the intervention group." 3

In a separate Milliman report in mid-2008, Fitch and Pyenson provided additional perspective to investments in disease management and wellness programs by pointing out that "many wellness programs appear to be experiments on employees" rather than interventions with measurable outcomes. ${ }^{16}$ Second, since wellness programs target primarily persons without illness, medical claims are not helpful in measuring cost outcomes (e.g., about $11 \%$ of health plan beneficiaries will have no medical claims in a given year) or identifying potential candidates. Third, health risk assessment (HRA) questionnaires that measure health status may be useful in identifying a subset of the population that may benefit from wellness programs, but there are at least 3 factors that mitigate the utility of using HRAs to measure wellness: (a) significant incentives will be necessary to achieve a significant response rate, particularly among dependents, (b) self-reported data will likely be of lower quality since there are typically no audits or rules for ensuring data quality, and (c) self-selection bias is inevitable in HRA response and wellness program participation (i.e., people who participate in wellness programs will tend to be more motivated); so nonparticipants in wellness programs will 
not constitute a good control group for evaluation of a wellness program.

Fitch and Pyenson's observations are consistent with a problem identified by the MHS program evaluators as a key factor in the program's failure to meet savings goals: "the [disease management vendors] may have substantially overestimated the impact of their intervention on their ability to reduce the stream of beneficiary utilization." ${ }^{3}$ Because the ratio of nondisease-related to disease-related inpatient admissions was about 3:1, the evaluators pointed out, "unless the [disease management] programs are able to target and prevent hospitalizations for causes other than [CHF] and diabetes, projected cost savings related to reduced hospitalizations are unlikely to materialize." ${ }^{3}$

\section{A1c and Cholesterol Biomarkers Pale Under a Bright Spotlight}

In a clinical trial with a particularly appropriate acronym, the ILLUMINATE (Investigation of Lipid Level Management to Understand its Impact in Atherosclerotic Events) trial results released in late 2007 shook our confidence in the value of serum cholesterol levels in predicting clinical end points and made clear why the manufacturer had stopped the ILLUMINATE trial in December 2006. ${ }^{17}$ The ILLUMINATE results included the finding that torcetrapib increased the risk of morbidity and mortality despite raising high-density lipoprotein cholesterol (HDL-C) and lowering low-density lipoprotein cholesterol (LDL-C). ${ }^{18}$ Compared with baseline values, 12 months of treatment with torcetrapib (a cholesteryl ester transfer protein [CETP] inhibitor) + atorvastatin in 7,534 patients at high cardiovascular risk, was associated with a mean $72.1 \%$ increase in HDL-C and a mean $24.9 \%$ decrease in LDL-C $(P<0.001$ for both comparisons). However, these favorable changes in serum cholesterol biomarkers were associated with an increased risk of cardiovascular events (hazard ratio $[\mathrm{HR}]=1.25,95 \%$ confidence interval $[\mathrm{CI}]=1.09-1.44, P=0.001)$ and all-cause death $(\mathrm{HR}=1.58,95 \%$ $\mathrm{CI}=1.14-2.19, P=0.006)$.

The second major blow to our confidence in cholesterol biomarkers came less than 5 months later when the results of the Ezetimibe and Simvastatin in Hypercholesterolemia Enhances Atherosclerosis Regression (ENHANCE) trial were released in the first week of April 2008, although our attention was piqued in December 2007 with the release of a Wall Street Journal investigation into the likely reasons for sandbagging the release of the ENHANCE trial results and a proposal by the drug study sponsors to change the definition of the primary end point in ENHANCE at the conclusion of the trial. ${ }^{19}$ After 24 months of treatment, mean (SD) LDL-C levels were 141.3 (52.6) mg per dL in the ezetimibe+simvastatin group and 192.7 (60.3) $\mathrm{mg}$ per $\mathrm{dL}$ in the simvastatin-only group $(P<0.01)$. Yet, among patients treated with ezetimibe+simvastatin, the mean intima-media thickness (IMT) for 6 carotid artery segments increased by $0.0111 \pm 0.0038 \mathrm{~mm}$, trending more than (as editors, we hear this too often despite the absence of statistical significance and simply could not bring ourselves to delete this point) the mean increase of $0.0058 \pm 0.0037 \mathrm{~mm}$ in the simvastatin-only group $(P=0.29) .{ }^{20}$ Similarly, the mean increase in the IMT of carotid and femoral arteries in the simvastatin + ezetimibe group $(0.0182 \pm 0.008 \mathrm{~mm})$ and the simvastatin-only group $(0.0033 \pm 0.0079 \mathrm{~mm})$ did not significantly differ $(P=0.15)$. Not many clinical trial results rise to this level of significance in challenging conventional wisdom, and the fact that greater reduction in LDL was not associated with reduction in the rate of thickening of the walls of carotid arteries was startling.

Brown and Taylor summarized the practical clinical results of the ENHANCE study in a commentary, which was consistent with the statement from the American College of Cardiology in January 2008: "First, achieve targets for levels of LDL and HDL cholesterol (or of the ratio of total cholesterol to HDL cholesterol) with the use of statins plus drugs that have shown clinical benefits when added to statins (e.g., nicotinic acid, fibrates, and bile acid sequestrants), as tolerated. Second, use ezetimibe in patients who, despite the above-mentioned therapy, do not achieve their individual targets." ${ }^{21}$ Brown and Taylor also compared the results of ENHANCE with ASAP (Atorvastatin vs. Simvastatin on Atherosclerosis Progression) conducted 6 years earlier: at 2 years, the increase in mean coronary artery IMT was $0.0058 \mathrm{~mm}$ for $80 \mathrm{mg}$ simvastatin in ENHANCE versus $0.036 \mathrm{~mm}$ for $40 \mathrm{mg}$ simvastatin monotherapy in ASAP (and $-0.031 \mathrm{~mm}$ in the ASAP $80 \mathrm{mg}$ atorvastatin group). While the 2 studies enrolled similar patients and used "nearly identical methods for measuring carotid-artery" IMT, the baseline IMT was $0.695 \mathrm{~mm}$ in the ENHANCE study versus $0.925 \mathrm{~mm}$ in ASAP. In commenting on ENHANCE, New England Journal of Medicine editors emphasized the paradox in the absence of difference in the mean IMT measures between the 2 groups despite 27\% lower mean LDL-C and lower C-reactive protein levels among those treated with combination simvastatin-ezetimibe therapy. The editors agreed with Brown and Taylor that ezetimibe should be "reserved for patients who cannot tolerate these agents" (niacin, fibrates, and resins) as add-on therapy when "diet, exercise, and a statin have failed to achieve the target."22

Finally, the distinct absence of consensus about the value of simply lowering LDL-C as a means to improve population health was evidenced by reaction to the recommendation of the American Pediatrics Association released in July 2008 for the use of statins in some children in an attempt to reduce heart attacks later in life. The recommendation was met immediately by "furious debate," including criticism such as that from a pediatric cardiologist, who observed that there are no data to support the use of statins for this purpose in this population. ${ }^{23}$

\section{ACCORD and ADVANCE Question the Value of the Biomarker A1c in Lower-Is-Better Strategy for Type 2 Diabetes}

In what may seem like a conspiracy against accepted biomarkers, the results from 2 large clinical trials recently shook confidence 
in the importance of Alc in predicting end point outcomes, after being used for more than 30 years to measure the degree of control of glucose metabolism. The surprising results of these 2 clinical trials became available at a time when our memory was still vivid of the threat to the lower-is-better mantra for LDL-C cholesterol and higher-is-better mantra for HDL-C.

On February 6, 2008, the National Heart, Lung, and Blood Institute of the National Institutes of Health (NIH) announced that it had for safety reasons stopped 18 months early the intensive-therapy treatment arm of a large, ongoing North American clinical trial that enrolled 10,251 participants with type 2 diabetes and high cardiovascular risk, defined as either a diagnosis of heart disease or 2 or more risk factors for heart disease. ${ }^{24}$ At 1 year in the Action to Control Cardiovascular Risk in Diabetes (ACCORD) study, the median Alc levels were $6.4 \%$ in the intensive-therapy group (target Alc below $6.0 \%$ ) versus $7.5 \%$ in the standard-therapy group (target Alc from $7.0 \%$ to $7.9 \%$ ). The first surprising finding was that there was no difference between the 2 groups in the number of patients who experienced a primary end point (nonfatal myocardial infarction [MI], nonfatal stroke, or cardiovascular-related death); 352 in the intensive-therapy group versus 371 in the standard-therapy group ( $\mathrm{HR}=0.90$, $95 \% \mathrm{CI}=0.78-1.04, \mathrm{P}=0.16) .{ }^{25}$ Second, there was a significant difference in the all-cause death rate, but not in the direction that was expected. The all-cause death rate was higher in the intensive-therapy group $(\mathrm{n}=257)$ compared with the standardtherapy group $(\mathrm{n}=203, \mathrm{HR}=1.22,95 \% \mathrm{CI}=1.01-1.46, P=0.04)$, which is equivalent to 14 deaths per 1,000 patients per year in the intensive-therapy group versus 11 per 1,000 in the standardtherapy group. Third, there were 2 additional outcomes that were not favorable: hypoglycemia requiring assistance and weight gain of more than $10 \mathrm{~kg}$ were more frequent in the intensive-therapy group $(P<0.001)$.

The unexpected outcomes in the ACCORD trial are significant from several perspectives. The sheer size of the trial—with 10,251 participants—and its randomized design lend confidence to the results. It is also important to note that the participants in the ACCORD trial were at high risk for cardiovascular problems, having been diagnosed with type 2 diabetes for at least 10 years and already with symptoms of heart disease or at least 2 risk factors such as high cholesterol and high blood pressure; the median Alc of the ACCORD participants was $8.1 \%$ at study entry. The ACCORD results made clear the questionable value of lowering Alc with intensive therapy to a target lower than 6.0\% and suggested a "previously unrecognized harm" associated with this strategy. ${ }^{25}$

\section{ADVANCE-Clearly Negative Results for the Reduction of A1c and Prevention of Macrovascular Events}

Following shortly on the heels of the termination by NIH of the intensive-therapy strategy in the ACCORD trial, the results of the Action in Diabetes and Vascular Disease: Preterax and Diamicron
Modified Release Controlled Evaluation (ADVANCE) were published ahead of print on June 6, 2008. ${ }^{26}$ ADVANCE investigators randomized 11,140 patients with type 2 diabetes to either standard glucose control or intensive glucose control to achieve an Alc of $6.5 \%$ or less. After a median of 5 years, the mean Alc was $6.5 \%$ in the intensive-therapy group $(n=5,571)$ and $7.3 \%$ in the standard-therapy group $(n=5,569)$. The combined microvascular event rate was $9.4 \%$ in the intensive-therapy group versus $10.9 \%$ in the standard therapy group ( $\mathrm{HR}=0.86,95 \% \mathrm{CI}=0.77-0.97$, $P=0.01$ ), primarily because of a reduction in the incidence of nephropathy (4.1\% vs. $5.2 \%, \mathrm{HR}=0.79,95 \% \mathrm{CI}=0.66-0.93$, $P=0.006)$, with no significant effect on retinopathy $(6.0 \%$ vs. $6.3 \%, P=0.50)$.

Intensive therapy was associated with a lower incidence of combined major macrovascular and microvascular events (18.1\% vs. $20.0 \%$ with standard control, $\mathrm{HR}=0.90,95 \% \mathrm{CI}=0.82-0.98$, $P=0.01$ ). But, the surprising findings were that there were no differences between the intensive-therapy group and the standardtherapy group in (a) the incidence of major macrovascular events ( $\mathrm{HR}=0.94$ with intensive therapy, 95\% CI=0.84-1.06, $P=0.32$ ), (b) death from cardiovascular causes ( $\mathrm{HR}=0.88$ with intensive therapy, $95 \% \mathrm{CI}=0.74-1.04, P=0.12$ ), or (c) all-cause death ( $\mathrm{HR}=0.93$ with intensive therapy, 95\% $\mathrm{CI}=0.83-1.06, P=0.28$ ). And, as with the ACCORD trial results, there were additional adverse outcomes associated with intensive therapy such as severe hypoglycemia $(2.7 \%$, vs. $1.5 \%$ in the standard-therapy group, $\mathrm{HR}=1.86,95 \% \mathrm{CI}=1.42-2.40, P<0.001$ ).

\section{MTM Programs Designed to Reduce Biomarkers}

Right in the middle of this renewed controversy about the value of the biomarkers in predicting clinical end points lands the current article by Stockl et al. in this issue of JMCP. ${ }^{27}$ Stockl et al. studied the effect of a Medicare Part D medication therapy management program (MTMP) intervention whose objective was to promote initiation of statin therapy in members with diabetes or CAD by sending educational materials and patient-specific information to physicians. Statin initiation rates were $12.1 \%$ in the intervention group and $7.3 \%$ in a comparison group $(P=0.001)$; the comparison group consisted of members who met all intervention group criteria except for the MTMP requirement that they be diagnosed with at least 3 of 5 chronic diagnoses of interest. The timing is perfect. Now, an even larger leap of faith is required to believe that Medicare beneficiaries with high medical care utilization and costs will experience end point clinical benefit from an intervention in which physicians are encouraged to add statin therapy to reduce LDL-C, among a host of likely risk factors. The leap of faith is larger when one considers that (a) the intervention described by Stockl et al. was not guided by actual LDL-C laboratory values, and (b) these patients are already incurring at least $\$ 4,000$ in annual pharmacy expenditures for Medicare Part D-covered medications.

The work by Stockl et al. is nevertheless important in showing 
us the results of one of the interventions apparently expected of managed care organizations in managing the costs and utilization of high-cost Medicare Part D beneficiaries via MTMP. Whether there is gold at the end of this rainbow will not be known for years although the disappointing results of the MHS demonstration suggest otherwise. In the meantime, we know that there are administrative costs involved in performing the intervention (estimated at $\$ 1.51$ per physician intervention by Stockl et al.) and an annual statin cost of $\$ 275$ per patient ( $\$ 23$ per month); Stockl et al. did not assess the additional costs of physician visits or laboratory tests associated with new statin therapy.

The calculation of return on investment set forth by Stockl et al. also becomes much different under a couple of revised assumptions. First, drug cost must be multiplied by a factor of about 4 if brand statin drugs are used instead of generic simvastatin, ${ }^{28}$ increasing direct costs for both the health plan and outof-pocket costs for Medicare beneficiaries. Second, Stockl et al. used the results of the Scandinavian Simvastatin Survival Study $(4 S)$ to derive the number needed to treat $(\mathrm{NNT}=11)$ with statin drug therapy for 5.4 years to prevent 1 major coronary event. Alternately, the PROspective Study of Pravastatin in the Elderly at Risk (PROSPER) trial, which randomized 5,804 elderly patients (aged 70-82 years) with either a history of or risk factors for cardiovascular disease to either placebo or pravastatin $40 \mathrm{mg}$ per day, demonstrated a 19\% reduction in the risk of nonfatal MI and coronary death with pravastatin treatment, ${ }^{29}$ and the absolute rates of the primary end point after a mean of 3.2 years of treatment were $16.2 \%$ in the placebo group and $14.1 \%$ in the pravastatin group, yielding an NNT of 48 . Substituting the $4 S$ results with the PROSPER results in the model used by Stockl et al. increases the direct drug cost to prevent 1 major coronary event from $\$ 16,335$ to $\$ 42,240$, easily overwhelming the estimated $\$ 28,990$ from 1 avoided major coronary event, before consideration of the more than 4-fold greater administrative cost associated with the need for about 1,000 interventions to obtain 48 new starts on statin therapy.

\section{Lower A1c Versus Cardiovascular Risk}

Also in this issue of JMCP and in the middle of attempts to determine the implications of ACCORD and ADVANCE, the article by Starner et al. lays out nicely for us the 5 safety warnings that occurred in 2007 for the 2 thiazolidinediones, pioglitazone, and rosiglitazone, and the opportunity that still exists for weighing benefit and harm in patients with type 2 diabetes who are treated with these drugs. ${ }^{30}$ In this post-marketing surveillance report, the authors found a $68 \%$ drop in rosiglitazone utilization from its peak of 99.1 claims per day per million members in February 2007, to 31.8 claims per day per million members in May 2008. However, there were still about 1 in 5 rosiglitazone patients at risk of a major cardiovascular event 1 year after 2 meta-analyses found an increased risk of MI in patients who had taken rosiglitazone ${ }^{31,32}$ and the release of a U.S. Food and Drug
Administration (FDA) safety alert on May 21, 2007, regarding the increase of MI associated with rosiglitazone. ${ }^{33}$ There were also about 1 in 50 users of pioglitzaone in May 2008 who had evidence of heart failure, but this incidence was down from 1 in 36 users in May 2007, 3 months before the black-box warning for exacerbation and precipitation of heart failure was added to the labels of pioglitazone and rosiglitazone. ${ }^{34}$

Deeper investigation of the ACCORD trial shows that rosiglitazone was used in $90 \%$ of the intensive-therapy group versus $58 \%$ in the standard-therapy group, but the ACCORD trial investigators concluded that there was no link between rosiglitazone use and the increased rates of death in the intensive-therapy group. Dluhy and McMahon opined in an editorial published with the ACCORD trial in June 2008 that these results do not vindicate rosiglitazone from the findings of the meta-analysis of Nissen and Wolski in which rosiglitazone was associated with increased risk of MI and nearly significant increased risk of cardiovascular death. ${ }^{35}$ These editors also concluded that the $3.5-\mathrm{kg}$ mean weight gain in the intensive-therapy group was explained by the use of thiazolidinediones and insulin in this group.

The observations of Dluhy and McMahon take us to a new awareness that glucose lowering alone does not predict a reduction in macrovascular events in patients with type 2 diabetes, at least in the first few years of treatment, when the results of ADVANCE, ACCORD, and the United Kingdom Prospective Diabetes Study (UKPDS) trials are considered together; for UKPDS, a reduction in cardiovascular events was not observed in patients with type 2 diabetes whose Alc was reduced from $8 \%$ to $7 \% .{ }^{36}$ Therefore, it is logical that nonglycemic factors such as hypertension, dyslipidemia, and hypercoagulability may have an additive effect in patients with type 2 diabetes, and "before new targets are defined, it is worth reflecting that the currently established targets for hyperglycemia, hypertension, and hyperlipidemia are achieved" in less than $10 \%$ of patients..$^{35}$ On the other hand, Dluhy and McMahon also raised a question about possible misclassification of some of the excess deaths in ACCORD attributed to "unexpected or presumed cardiovascular disease" as alternatively attributable to hypoglycemia.

\section{FDA Requests More Than A1c Lowering for Drug Approvals for Diabetes}

The significance of the unexpected results of ACCORD and ADVANCE were not lost on the FDA, which called a meeting of its Endocrinologic and Metabolic Drugs Advisory Committee on July 1-2, 2008. Invited speakers included Steven Nissen, MD, talking about the need for cardiovascular assessment prior to FDA approval of antidiabetic drugs, ${ }^{37}$ and attendees included Clifford Rosen, MD, who is critical of newer antidiabetic drugs on the market that have not shown therapeutic advances over existing drugs. ${ }^{38}$ The FDA's background memorandum ahead of the meeting of the Endocrinologic and Metabolic Drugs 
Advisory Committee included the conclusion that "reduced risk of macrovascular complications in type 2 diabetes has not yet been established for any of the currently available antidiabetic medications, including insulin." ${ }^{39}$ At the meeting, Dr. Nissen proposed that the FDA impose a higher standard for approval of antidiabetic drugs, that new drugs must show no increased risk of cardiovascular disease. ${ }^{40}$ The FDA panel voted 14 to 2 on July 2, 2008, to require all new diabetes drugs to show no increased risk of cardiovascular harm. ${ }^{41}$

\section{The Future of Biomarkers A1c and LDL-C and Risk Factor Management}

The sometimes disappointing results of rigorous tests of programs intended to increase adherence to guideline-based therapies and goals, including attainment of biomarker measures, may in part reflect limitations of the guidelines themselves. A 1999 evaluation of 279 guideline documents published between 1985 and 1997 found that the mean rate of adherence to methodological standards for identification and summary of evidence was only $33.6 \%$; only $16.8 \%$ of guideline documents specified the method for identifying scientific evidence, only $14.3 \%$ specified the time period covered by the evidence review, only $60.2 \%$ quantified benefits and harms associated with treatment options, and a shockingly low $12.9 \%$ graded recommendations according to the strength of the evidence. ${ }^{42}$ The tenuous relationship of biomarkers such as Alc or LDL-C and cardiovascular events or death has been recognized in guidelines for the conduct of research in cost-effectiveness analysis. Three years ago, a task force on good research practices recommended against the use of intermediate end points such as the degree of LDL-C reduction when assessing cost-effectiveness. ${ }^{43}$

Starfield et al. put the recently discovered lack of value of biomarkers, such as Alc and serum cholesterol, into broader perspective: over the last 3 decades, disease prevention has become risk factor management. ${ }^{44}$ The evolution in this thinking can be traced back to 1978, when prevention of disease (primary prevention) expanded to include interventions for the early detection and treatment of disease (secondary prevention), and later to the emergence of interventions "to improve function, minimize impact, and delay complications" (tertiary prevention). ${ }^{45}$ Today, we have the conceptual framework of quarternary prevention, but there is a lack of consensus regarding what this means exactly.

Quarternary prevention was defined in 2003 by the world organization of family physicians (WONCA) as "an action taken to identify a patient at risk of over-medicalization, to protect him from new medical invasion, and to suggest to him interventions which are ethically acceptable." ${ }^{46}$ This definition clearly recognizes the additional health risk from adverse effects associated with interventions intended to slow the progression of disease, consistent with the call by Nissen in early July 2008 for the FDA to ensure that new diabetes drugs are not approved before their safety is proven in not increasing the risk of adverse cardiovascular outcomes, while managing Alc.

However, there is a large challenge to embracing a risk-versusbenefit conceptual construct in the conduct of interventions in pursuit of population health. One needs to look no further than the disparate definitions of quarternary prevention from different segments of the health care machine. For example, the WONCA definition of quarternary prevention is at odds with the definition from cardiovascular medicine, "rehabilitation or restoration of function" for "those with severe cardiovascular dysfunction," 47 and with the definition from public health advocates, ${ }^{48}$ which essentially focuses on learning from our mistakes (interventions) in quality assurance and quality improvement.

There is presently a confluence of events that create an important opportunity to step back and survey the evidence for benefit versus risk in pursuit of disease prevention and disease management. At the least, conventional wisdom regarding the connection between biomarkers such as Alc and serum cholesterol and clinical end points has been exposed as not necessarily wise nor conventional. Conventional wisdom regarding the effectiveness of chronic care management in improving end point outcomes is being challenged as well and will require substantial rethinking and the gathering of high-quality evidence about the populations in which interventions are most likely to be effective. Now is also the time to reassess the transition that has occurred over the last 2 decades from disease management to pre-disease interventions based on blood pressure, serum cholesterol, and blood sugar. Current thresholds for these 3 biomarkers place $97 \%$ of all U.S. adults aged 50 years or older "at risk" by 1 or more of these biomarkers, but "only $8 \%$ of cardiovascular disease will occur in individuals with any combination of them." ${ }^{44}$ There is also the often overlooked fact that risk factors are not independent. Following the evidence is certainly leading us to some unexpected findings and reminding us that preventing specific diseases and chasing pre-disease markers are not the same as promoting health.

\section{Authors}

Frederic R. Curtiss, PhD, RPh, CEBS, is Editor-in-Chief, and

Kathleen A. Fairman, MA, is Associate Editor and Senior Methodology Reviewer of the Journal of Managed Care Pharmacy.

AUTHOR CORRESPONDENCE: Frederic R. Curtiss, PhD, RPh, CEBS, Academy of Managed Care Pharmacy, 100 North Pitt St., Suite 400, Alexandria, VA 22314. Tel.: 830.935.4319;

E-mail:fcurtiss@amcp.org

\section{DISCLOSURES}

The authors report no conflicts of interest related to the subjects or products discussed in this article. 


\section{REFERENCES}

1. Narcissus (mythology). Wikipedia.com. Available at: http://en.wikipedia. org/wiki/Narcissus_(mythology). Accessed July 15, 2008.

2. Ullman K. Medicare dives into disease management: pilot program coordinates care of diabetes, other chronic illnesses. DOC News. 2006;3(9):1. Available at: http://docnews.diabetesjournals.org/cgi/content/full/3/9/l-a. Accessed July 15, 2008.

3. McCall N, Cromwell J, Bernard S. Evaluation of Phase I of Medicare Health Support (Formulary Voluntary Chronic Care Improvement) Pilot Program Under Traditional Fee-for-Service Medicare: Report to Congress. June 2007. Available at www.cms.hhs.gov/reports/downloads/McCall.pdf. Accessed July 15, 2008.

4. Mattke S. Is there a disease management backlash? Am J Manag Care. 2008;14(6):349-50

5. Fitch K, Iwasaki K, Kalin D, Pyenson B. Cost trends for chronic-condition cohorts with Medicare benefits. Milliman Research Report. May 2008. Available at: www.milliman.com/expertise/healthcare/publications/rr/pdfs/ cost-trends-for-chronic-condition-RR5-1-08.pdf. Accessed June 17, 2008.

6. Foote SM. Population-based disease management under fee-for-service Medicare. Health Aff (Millwood). 2003;suppl Web exclusives W3-342-56.

7. Crippen DL. Disease management in Medicare: Data analysis and benefit design issues. Congressional Budget Office Testimony before the Special Committee on Aging, U.S. Senate, September 19, 2002. Available at: www. cbo.gov/doc.cfm?index=3776\&ty\%20pe=0. Accessed July 15, 2008.

8. Goetzel RZ, Ozminkowski RJ, Villagra VG, Duffy J. Return on investment in disease management: a review. Health Care Financ Rev. 2005;26(4):1-19.

9. Rubin RJ, Dietrich KA, Hawk AD. Clinical and economic impact of implementing a comprehensive diabetes management program in managed care. J Clin Endocrinol Metab. 1998;83(8):2635-42.

10. Domurat ES. Diabetes managed care and clinical outcomes: the Harbor City, California Kaiser Permanente Diabetes Care System. Am J Manag Care. 1999;5:1299-307

11. Warsi A, Wang PS, LaValley MP, Avorn J, Solomon DH. Self-management education programs in chronic disease: a systematic review and methodological critique of the literature. Arch Intern Med. 2004;164:1641-49.

12. Rich MW, Beckham V, Wittenberg C, Leven CL, Freedland KE, Carney RM. A multidisciplinary intervention to prevent the readmission of elderly patients with congestive heart failure. N Engl J Med. 1995;333(18):1190-95.

13. Stewart S, Vandenbrook AJ, Pearson S, Horowitz JD. Prolonged beneficial effects of a home-based intervention on unplanned readmissions and mortality among patients with congestive heart failure. Arch Intern Med. 1999;159(3):257-61.

14. Cline CMJ, Israelsson BYA, Willenheimer RB, Broms K, Erhardt LR. Cost effective management programme for heart failure reduces hospitalization. Heart. 1998;80:442-46.

15. Laramee AS, Levinsky SK, Sargent J, Ross R, Callas P. Case management in a heterogenous congestive heart failure population: A randomized controlled trial. Arch Intern Med. 2003;163:809-17.

16. Fitch K, Pyenson B. Taking stock of wellness. Benefits Q. Second quarter, 2008:34-40. Available at: www.milliman.com/expertise/healthcare/ publications/published/taking-stock-of-wellness-PA04-01-8.php. Accessed June 22, 2008.

17. Krumholz HM, Lee TH. Redefining quality-implications of recent clinical trials. N Engl J Med. 2008;358(24):2537-40.

18. Barter PJ, Caulfield M, Eriksson M, et al., for the ILLUMINATE Investigators. Effects of torcetrapib in patients at high risk for coronary events. N Engl J Med. 2007;357(21):2109-22.

19. Winslow R. Stakes remain high in Merck, Schering-Plough drug study. Wall Street Journal. December 17, 2007:B3.
20. Kastelein JJP, Akdim F, Stroes ESG, et al. for the ENHANCE Investigators. Simvastatin with or without ezetimibe in familial hypercholesterolemia. N Engl J Med. 2008;358(14):1431-43. (Erratum. N Engl J Med. 2008;358(18):1977.)

21. Brown BG, Taylor AJ. Does ENHANCE diminish confidence in lowering LDL or in ezetimibe? N Engl J Med. 2008;358(14):1504-07.

22. Drazen JM, Jarcho JA, Morrissey S, Curfman GD. Cholesterol lowering and ezetimibe. N Engl J Med. 2008;358(14):1507-08.

23. Parker-Pope T. 8-year-olds on statins? A new plan quickly bites back. New York Times. July 8, 2008.

24. Anonymous. For safety, NHLBI changes intensive blood sugar treatment strategy in clinical trial of diabetes and cardiovascular disease. NIH News. February 6, 2008. Available at: www.nih.gov/news/health/feb2008/nhlbi-06. htm. Accessed February 7, 2008

25. Gerstein HC, Miller ME, Byington RP, et al. for the Action to Control Cardiovascular Risk in Diabetes Study Group. Effects of intensive glucose lowering in type 2 diabetes. N Engl J Med. 2008;358(24):2545-59.

26. The ADVANCE Collaborative Group. Intensive blood glucose control and vascular outcomes in patients with type 2 diabetes. N Engl J Med. 2008; 358(24):2560-72.

27. Stockl KM, Tjioe D, Gong S, Stroup J, Harada ASM, Lew HC. Effect of an intervention to increase statin use in Medicare members who quality for a medication therapy management program. J Manag Care Pharm. 2008; 14(6):532-40.

28. Drug prices from www.drugstore.com. $\$ 25.32$ per 30-day supply for simvastatin $40 \mathrm{mg}$ per day versus $\$ 93.31$ per 30 -day supply for Crestor $10 \mathrm{mg}$ per day versus $\$ 111.99$ per 30-day supply of Lipitor $20 \mathrm{mg}$. Accessed July 6, 2008.

29. Shepherd J, Blauw GJ, Murphy ME, et al. Pravastatin in elderly individuals at risk of vascular disease (PROSPER): a randomised controlled trial. Lancet. 2002;360:1623-30.

30. Starner CI, Schafer JA, Heaton AH, Gleason PP. Rosiglitazone and piolglitazone utilization from January 2007 through May 2008 associated with four risk-warning events. J Manag Care Pharm. 2008;14(6):523-31.

31. Nissen SE, Wolski K. Effect of rosiglitazone on the risk of myocardial infarction and death from cardiovascular causes. N Engl J Med. 2007; 356(24):2457-71. Available at: http://content.nejm.org/cgi/content/full/ 356/24/2457. Accessed July 6, 2008.

32. Rubenstein S. Glaxo letter defends Avandia. Wall Street Journal. May 31, 2007:D6.

33. FDA News. FDA issues safety alert on Avandia. May 21, 2007 (P07-88). Available at: www.fda.gov/bbs/topics/NEWS/2007/NEW01636.html. Accessed July 14, 2008.

34. FDA News. Manufacturers of some diabetes drugs to strengthen warning on heart failure risk. August 14, 2007. Available at: www.fda.gov/bbs/topics/ NEWS/2007/NEW01683.html. Accessed July 6, 2008.

35. Dluhy RG, McMahon GT. Intensive glycemic control in the ACCORD and ADVANCE trials. N Engl J Med. 2008;358(24):2630-33.

36. Anonymous. Effect of intensive blood-glucose control with metformin on complications in overweight patients with type 2 diabetes (UKPDS 34): UK Prospective Diabetes Study (UKPDS) Group. Lancet. 1998;352:854-65. (Erratum. Lancet. 1998;352:1558.)

37. U.S. Food and Drug Administration. Center for Drug Evaluation and Research (CDER). Endocrinologic and Metabolic Drugs Advisory Committee Meeting. July 1-2, 2008. Available at: www.fda.gov/ohrms/dockets/ac/08/ agenda/2008-4368al-draft.pdf. Accessed July 2, 2008.

38. Favole JA, Mundy A, Diabetes drugs face tougher rules. Wall Street Journal. June 28-29, 2008:B7. 
39. U.S. Food and Drug Administration. Center for Drug Evaluation and Research. Background introductory memorandum. The role of cardiovascular assessment in the pre-approval and post-approval settings for drugs and biologics developed for the treatment of type 2 diabetes mellitus. Guidance for industry: diabetes mellitus: developing drugs and therapeutic biologics for treatment and prevention. February 13, 2008. Available at: www.fda.gov/ohrms/dockets/ac/08/briefing/2008-4368bl-01-FDA.pdf. Accessed July 2, 2008.

40. Favole JA. FDA urged to test diabetes drugs' heart risk. Wall Street Journal. July 2, 2008:D3.

41. Associated Press. FDA panel urges upgrade of diabetes-drug standards. Wall Street Journal. July 3, 2008:B11.

42. Shaneyfelt TM, Mayo-Smith MF, Rothwangl J. Are guidelines following guidelines? The methodological quality of clinical practice guidelines in the peer-reviewed methodological literature. JAMA. 1999;281(20):1900-05.

43. Ramsey S, Willke R, Briggs A, et al. Good research practices for costeffectiveness analysis alongside clinical trials: The ISPOR RCT-CEA task force report. Value Health. 2005;8(5):521-33.
44. Starfield B, Hyde J, Gervas J, Health I. The concept of prevention: a good idea gone astray? J Epidemiol Community Health. 2008;62:580-83.

45. National Public Health Partnership. Preventing chronic disease: a strategic framework. Background paper. Melbourne, Australia: National Public Health Partnership; 2001.

46. Bentzen N. WONCA Dictionary of General/Family Practice. Copenhagen, Denmark: Laegeforeningens, Forlag; 2003. Available at: www.globalfamily doctor.com/dictionaryW/Dictionary\%20of\%20General-Family\%20Practice. htm. Accessed July 25, 2008.

47. Association of state and territorial chronic disease program directors. Defining roles for public health in secondary/tertiary prevention of cardiovascular disease. Cited in Mensah GA, Dietz WH, Harris VB, et al. Centers for Disease Control and Prevention. Prevention and control of coronary heart disease and stroke-nomenclature for prevention approaches in public health: a statement for public health practices from the Centers for Disease Control and Prevention. Am J Prev Med. 2005;29(5 suppl 1):152-57.

48. Gofrit ON, Sherner J, Leibovici D, et al. Quarternary prevention: a new look at an old challenge. Isr Med Assoc J. 2000;2(7):498-500.

\section{Letters to the Editor}

JMCP welcomes letters that serve to clarify subjects published in previous issues of the Journal or regarding subject matter of interest to managed care professionals. Letters in JMCP are not peer reviewed but are subjected to editorial review. Letters should be prepared in a word processing program, preferably Microsoft Word, and submitted electronically at jmcp.msubmit.net. See JMCP Author Guidelines at www.amcp.org for details. 